\title{
Statcounter Sebagai Monitoring Aktivitas Website PESSTA+ Pada Perguruan Tinggi
}

\section{Statcounter as Monitoring of PESSTA + Website Activities in Higher Education}

\author{
Indri Handayani $^{1}$, Erick Febryanto ${ }^{2}$, Egi Wijatriana Bachri ${ }^{3}$ \\ Jurusan Sistem Informasi, STMIK Raharja, Tangerang \\ e-mail: ${ }^{1}$ indri@ raharja.info,${ }^{2}$ erick@ raharja.info,${ }^{3}$ wijatriana@ raharja.info
}

\begin{abstract}
Abstrak
Tingkat aktivitas suatu website merupakan suatu hal yang berperan penting untuk dapat di ukur terutama untuk website yang pada dasarnya di buat dan di alokasikan untuk memberikan pelayanan dan informasi bagi pengunjung nya. Website PESSTA+ pada Perguruan Tinggi Raharja, merupakan sistem validasi Penilaian Objektif Sidang yang dapat di akses secara mandiri dan online, sehingga Mahasiswa dapat melakukan submit di mana pun dan kapanpun. Yang di tunjukkan untuk mempermudah mahasiswa dalam memenuhi 10 point Penilaian Objektif saat Sidang TA/Skripsi. Pada website PESSTA+ belum ada nya sistem yang dapat memonitoring seberapa banyak visitors yang mengunjungi website PESSTA+. Dari permasalahan yang ada, peneliti mengambil tema penelitian penerapan aplikasi stat counter sebagai alat monitoring aktivitas pada website PESSTA+. Penelitian ini menggunakan metode pengumpulan data dengan menggunakan teknik observasi, wawancara, serta studi pustaka. Pada teknik observasi dilakukan secara langsung dengan melakukan monitoring pada website PESSTA+. Metode wawancara dilakukan bersama beberapa narasumber dari pengelola website PESSTA+ saat ini. Dengan adanya sistem stat counter ini diharapkan pengelola dapat mengetahui seberapa banyak tingkat aktivitas yang ada pada sistem PESSTA+ dan tidak hanya itu pengunjung pun dapat membantu pengelola dalam hal memonitoring aktivitas website secara detail karena pada dasarnya Stat Counter juga menampilkan data dan informasi mengenai aktivitas setiap pengunjung secara rinci.
\end{abstract}

Kata kunci: Single Sign On (SSO), PESSTA+, Stat counter

\begin{abstract}
The level of activity of a website is an important role to be measured especially for websites that are basically created and allocated to provide services and information for visitors. PESSTA + website at Raharja College, is a validation system of the Objective Session Assessment which can be accessed independently and online, so that students can submit it anywhere and anytime. What is shown is to facilitate students in meeting the 10 points of Objective Assessment during the TA / Thesis Session. On the PESSTA + website there is no system that can monitor how many visitors visit the PESSTA + website. From the existing problems, researchers took the theme of the research on the application of a stat counter as a monitoring tool for activities on the PESSTA + website. This study uses data collection methods using observation, interviews, and literature studies. Observation techniques are carried out directly by monitoring the PESSTA + website. The interview method was conducted with several speakers from the current PESSTA + website manager. With this stat counter system, the manager is expected to know how much level of activity there is in the PESSTA + system and not only that visitors can help managers in monitoring the activity of the website in detail
\end{abstract}


because basically Stat Counter also displays data and information about the activity of each visitor detailed.

Keywords: Single Sign On (SSO), PESSTA+, Stat counter

\section{PENDAHULUAN}

Informasi merupakan hal yang sangat memiliki peran penting dan sangat di butuhkan oleh manusia saat ini, informasi juga dapat untuk mengambil sebuah keputusan dan tergantung dari bagaimana suatu informasi tersebut dapat dipecahkan. Perkembangan informasi ini tentunya tidak luput dari adanya Perkembangan Teknologi Informasi saat ini yang jelas sudah sangat maju. Informasi saat ini dapat di akses kapan pun dan di mana pun dengan bantuan Teknologi Informasi yang sudah ada saat ini.

Dengan berkembangnya Teknologi Informasi saat ini sangat memiliki peran penting dalam meningkat kan laju perputaran informasi di masyarakat. Dalam hal lain Teknologi Informasi juga sangat berperan besar dalam menjawab permintaan masyarakat akan informasi yang akurat dan cepat. Dalam Perkembangan Teknologi tidak hanya masyarakat yang menggunakannya tetapi institusi pendidikan juga ikut berperan dalam penggunaan Perkembangan Teknologi.

Perguruan Tinggi Raharja merupakan institusi pendidikan yang ikut serta berperan dalam penggunaan Teknologi Informasi sebagai alat untuk menyebarkan informasi di dalam setiap aspek kegiatan yang berada di dalam Perguruan Tinggi Raharja.

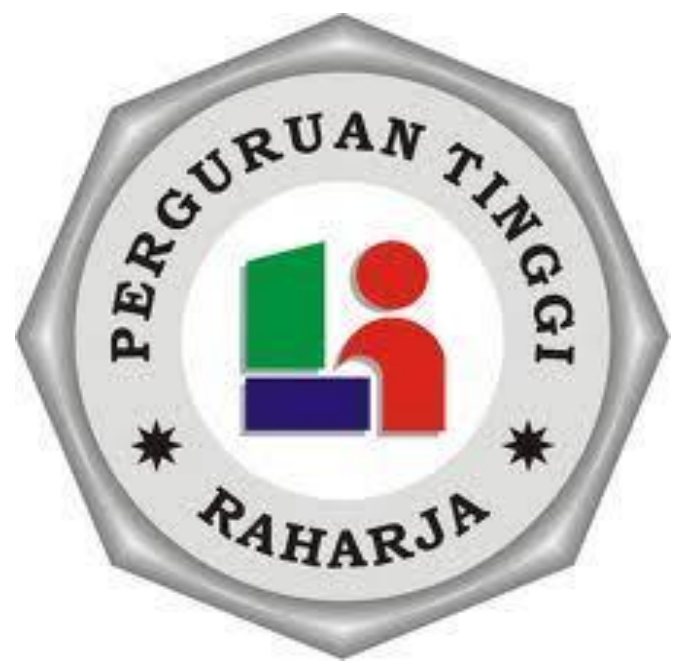

Gambar 1. Logo Perguruan Tinggi Raharja

Gambar 1 merupakan logo dari Perguruan Tinggi Raharja, yang merupakan salah satu Perguruan Tinggi yang bergerak dalam bidang Teknologi Informasi, Perguruan Tinggi Raharja memiliki hubungan yang sangat erat dengan perkembangan Teknologi Informasi di mana Teknologi Informasi tersebut sangat memiliki peran penting dalam sistem perkuliahan di Perguruan Tinggi Raharja. Salah satu fungsi nya sebagai alat untuk menyebarkan informasi perkuliahan dan informasi-informasi lain nya yang berkaitan tentang Perguruan Tinggi.

Menurut Muslihudin, dkk (2016 : 9), Informasi merupakan data yang di olah menjadi bentuk yang berguna untuk membuat keputusan. Informasi berguna untuk membuat keputusan Karena informasi menurunkan ketidakpastian (atau meningkatkan pengetahuan). Informasi menjadi penting karena berdasarkan informasi itu para pengelola dapat mengetahui kondisi objektif perusahaannya. Informasi tersebut merupakan hasil pengolahan data atau fakta yang dikumpulkan dengan metode ataupun cara-cara tertentu.

Website merupakan situs sistem informasi yang dapat diakses dengan cepat. Website lahir dari adanya perkembangan zaman saat ini dari bidang teknologi informasi dan komunikasi. 
Website telah menjadi media penyampaian informasi bagi bermacam perusahaan, sekolah, tidak terkecuali pada organisasi.

Website PESSTA+ Perguruan Tinggi Raharja, merupakan suatu sistem validasi penilaian Objektif Sidang yang dapat di akses secara mandiri dan online, sehingga Mahasiswa dapat melakukan submit di mana saja dan kapan saja. Yang ditujukan untuk mempermudah mahasiswa dalam memenuhi 10 point Penilaian Objektif pada saat Sidang TA/Skripsi. PESSTA+ sendiri merupakan kepanjangan dari Penilaian Sidang Skripsi dan Tugas Akhir).

Dengan adanya website PESSTA+ pada Perguruan Tinggi Raharja ini sangat membantu setiap Pribadi Raharja khususnya kepada mahasiswa yang ingin menyelesaikan Skripsi dan Tugas Akhir. Pada PESSTA+ mahasiswa dapat menggunakan beberapa fitur yang ada pada PESSTA+ yaitu Validasi berkas Raharja Career, Validasi kutipan Jurnal, Validasi Widuri, Validasi Bimbingan Konsultasi, Validasi Widuri, Validasi Sertifikat Tridharma, Validasi Poster Session, Validasi Berkas Sidang, Validasi Sertifikat, Validasi Jurnal.

Stat counter merupakan salah satu dari sekian banyak penyedia visitor counter yang dapat di akses secara gratis. Salah satu keunggulan pada stat counter adalah angka visitor counter diambil berdasarkan unique visit dan beberapa statik yang dihasilkan stat counter merupakan data dan informasi yang dapat dijadikan bahan pertimbangan berkualitas dan juga dapat dijadikan acuan untuk pengembangan website PESSTA+ pada Perguruan Tinggi Raharja, sehingga dari segi perhitungan pengunjung stat counter dapat memiliki nilai yang lebih baik.

Pada saat ini statcounter sudah banyak digunakan oleh beberapa website untuk memonitoring pengunjung yang mengunjungi website tersebut. Maka dari itu, peneliti ingin menerapkan sistem statcounter pada PESSTA+ agar dapat memantau seberapa banyak visitors yang menggunakan PESSTA+. Sebelum nya pengelola tidak dapat melihat seberapa banyak pengunjung yang membuka website PESSTA+. Dengan adanya Statcounter ini pengelola juga dapat melihat seberapa menarik dan seberapa manfaat website PESSTA+ tersebut.

\section{METODE PENELITIAN}

Metode penelitian yang diterapkan untuk penelitian kali ini adalah menggunakan Metode Perancangan, Metode Pengumpulan data dan Metode Studi Pustaka.

\section{Metode Perancangan}

Metode Perancangan menggunakan UML. Unified Modeling Language (UML) adalah metode perancangan secara visual sebagai sarana untuk merancang dan membuat software yang berorientasi pada objek. Karena UML ini merupakan bahasa visual untuk permodelan bahasa berorientasi pada objek, maka semua elemen dan diagram berbasiskan kepada paradigma object orientied [3].

\section{Metode Pengumpulan Data}

Pengumpulan data pada penelitian ini dengan menggunakan teknik observasi, wawancara, serta studi pustaka. Pada teknik observasi dilakukan secara langsung dengan melakukan monitoring pada website PESSTA+. Wawancara dilakukan bersama beberapa narasumber dari pengelola website PESSTA+ saat ini.

\section{Metode Studi Pustaka}

Studi Pustaka merupakan metode yang digunakan untuk mengumpulkan informasi yang relevan sesuai dengan topik dan permasalahan yang menjadi obyek penelitian. Upaya dalam meningkat kan Visitor Count sebagai alat monitoring aktivitas website PESSTA+, terdapat beberapa Studi Pustaka yang telah disiapkan untuk mengidentifikasi kesenjangan, menghindari pengulangan, dan meneruskan penelitian yang sebelumnya telah dilakukan. Beberapa literature review diantaranya sebagai berikut:

a. Penelitian yang telah dilakukan oleh Indri Handayani, Maulana Sani dan Dewi Ratna Sari dari Perguruan Tinggi Raharja pada tahun 2016 yang berjudul "Penerapan Stat counter sebagai Alat Monitoring Aktivitas Website Hibah Perguruan Tinggi Raharja". Dalam penelitian yang mereka lakukan ini membahas tentang penerapan stat counter sebagai alat 
hitung jumlah pengunjung yang mengunjungi Website Hibah pada Perguruan Tinggi Raharja.

b. Penelitian yang dilakukan oleh Alfred Tenggono, Yovan Wijaya, Erick Kusuma dan Welly dari STMIK PalComTech Palembang pada SISFOTENIKA Vol.5 No.2 tahun 2015 yang berjudul "Sistem Monitoring dan Peringatan Ketinggian Air Berbasis Web dan SMS Gateway". Dalam penelitian nya mereka membahas tentang penerapan sistem monitoring dan juga sebagai peringatan tentang ketinggian air di daerah Palembang. Dengan diterapkan nya sistem monitoring ini dapat memonitoring ketinggian air dan memberi peringatan kepada pengguna yang dapat di akses melalui Web maupun SMS Gateway.

c. Penelitian yang telah dilakukan oleh MH Jewel, MN Islam dan MJ Hasan dari EWU Institutional Repository pada tahun 2017 yang berjudul "Automatic Room Light Control Using Bidirectional Visitor Counter and Gas Detection". Dalam penelitian yang mereka lakukan ini membahas tentang penerapan untuk mendeteksi tingkat gas atau asap di ruang dapur dan mengambil tindakan yang diperlukan untuk melindungi pengaktifan. Ketika seseorang masuk ke ruangan, beban akan mendapatkan kekuatan dan dapat dijalankan oleh switch mereka. Sirkuit balasan dapat menghitung jumlah orang yang tinggal di ruangan. Jika seseorang masuk ke ruangan, penghitung akan bertambah dan jika seseorang pergi ruangan konter akan dikurangi. Setelah orang terakhir meninggalkan ruangan, nilai dari counter akan menjadi nol dan beban akan terputus dari power. Sensor gas selalu merasakan gas atau tingkat asap di ruang dapur. Jika tingkat gas / asap di atas yang telah ditentukan ambang, itu akan memberi suara alarm. Terlebih lagi, jika tidak ada orang di ruangan itu, kekuatan memainkan switch akan secara otomatis OFF.

d. Penelitian yang telah dilakukan oleh Ifadah Amalia dan Karmilasari dari Universitas Gunadarma, Depok pada tahun 2011 yang berjudul "Analisis Kepopuleran iMe UKM dengan metode Survey dan Perangkat Bantu SEO dan Trance Visitor". Dalam penelitian yang mereka lakukan ini membahas tentang analisis kepopuleran iMe UKM menggunakan metode survey yang ditujukan kepada pengunjung iMe untuk memberikan penilaian secara kualitatif, dan juga pengamatan secara langsung menggunakan alat bantu yaitu berupa trace visitor dan juga menerapkan SEO pada iMe UKM tersebut.

e. Penelitian yang dilakukan oleh Muhammad Andang, Emy Setyaningsih dari Jurnal Momentum pada tahun 2015 yang berjudul "SISTEM INFORMASI MONITORING KERETA API BERBASIS WEB SERVER MENGGUNAKAN LAYANAN GPRS ". Dalam penelitian yang mereka lakukan membahas tentang rancangan web base server sebagai sistem pemantaun secara on-line yang memanfaatkan jaringan GSM menggunakan layanan GPRS. Komunikasi server dengan black box (alat pemantau) menggunakan teknologi yang berbasis raw socket (via UPD/TCP). Alat pemantau pada penelitian ini dianggap sebagai client yang terkoneksi ke server, sehingga lokasi koordinat kereta dapat divisualisasikan pada halaman web yang telah dibuat dalam bentuk peta digital menggunakan Google Maps dan marker..

f. Penelitian yang telah dilakukan oleh Gaurav Waradkar, dkk pada Imperial Journal of Interdisciplinary Research (IJIR) Vol -2, Issue -4, tahun 2016 dalam penelitiannya yang berjudul "Automated Room Light Controller with Visitor Counter". Penelitian nya kali ini membahas tentang penerapan visitor counter untuk alat monitoring pengambilan keputusan pada sistem penarangan otomatis pada suatu ruangan, pada implementasi nya sistem penerapan suatu ruangan ini bergantung kepada ada atau tidak nya orang (visitor) dalam ruangan, tetapi tidak semudah itu, karena penelitian tingkat penerangan dan banyaknya penerangan yang aktif berdasarkan banyaknya orang (visitor) di ruangan tersebut. Dan juga sebaliknya hal ini diterapkan di mana penerangan akan mati jika orang(visitor) tersebut meninggal kan ruangan

g. Penelitian yang dilakukan oleh Al-Radaideh, AR Al-Ali, S Bheiry dari IEEE Xplore pada tahun 2015 yang berjudul "A wireless sensor network monitoring system for highway 
bridges". Dalam penelitian nya mereka membahas tentang Pemeliharaan jembatan dan manajer infrastruktur dapat dengan mudah menggunakan aplikasi ini untuk menjaga kinerja dan keamanan struktur vital ini. Makalah ini menyajikan sistem jaringan sensor nirkabel otonom untuk memantau kesehatan struktural di jembatan jalan raya. Sistem yang diusulkan terdiri dari Unit Akusisi Data (DAQ) nirkabel, jaringan publik seluler, evaluasi data kesehatan struktural, middleware manajemen, GIS dan modul antarmuka pengguna grafis. Sensor di DAQ mengumpulkan tanda-tanda kesehatan jembatan dan mengirimkannya segera melalui jaringan mobile publik ke manajemen dan evaluasi middleware untuk diproses lebih lanjut. Berdasarkan skala peringkat inventarisasi jembatan nasional, mesin berbasis logika fuzzy peringatan dini dikembangkan untuk memproses status jembatan tertentu dan memperingatkan operator yang bersangkutan mengenai kelainan apa pun.

h. Penelitian yang dilakukan oleh Jurista Purnama jumri dari Universitas Tanjungpura pada Jurnal Untan 2013 yang berjudul "Perancangan Sistem Monitoring Konsultasi Bimbingan Akademik Mahasiswa dengan Notifikasi Realtime Berbasis SMS Gateway" Dalam penelitian yang dilakukan oleh Jurista membahas tentang penerapan sistem monitoring saat konsultasi bimbingan antara mahasiswa dan dosen melalui Notifikasi yang realtime pada SMS Gateway.

i. Penelitian yang dilakukan oleh Decy Nataliana, Iqbal Syamsu dan Galih Giantara dari Teknik Elektro Institut Teknologi Nasional Bandung pada Jurnal ELKOMIKA Vol 2 No 1 tahun 2014 yang berjudul "Sistem Monitoring Parkir Mobil menggunakan Sensor Infared berbasis RASPBERRY PI" Dalam penelitian yang mereka lakukan membahas tentang merancang dan merealisasikan sistem monitoring pada perparkiran dengan memiliki fasilitas untuk pemilihan area parkir dengan berbasis Raspberry Pi dan juga menggunakan manfaat infared sebagai sensor sistem monitoring tersebut agar sesuai dengan tujuan yang telah mereka tentukan.

j. Penelitian yang dilakukan oleh Owlena, adharul dan eka maulana dari Jurnal Mahasiswa TEUB pada tahun 2017 melakukan penelitian untuk TugaS Akhir yang berjudul " SISTEM SWITCHING DAN MONITORING TEGANGAN DAN ARUS PADA SMART GRID BERBASIS RASPBERRY PI 3 TERINTEGRASI DENGAN MEDIA SOSIAL DAN WEBSITE" pada penelitian yang di lakukan membahas tentang proses pengiriman data pada sistem monitoring dan swicthing smart grid adalah secara wireless dan dapat diakses pada laman website, Google Drive dan media sosial yaitu Telegram. Dengan demikian, monitoring dan switching smart grid lebih mudah diakses dan dapat dikomunikasikan secara jarak jauh. Sistem tersebut membutuhkan sebuah web server yang dijalankan oleh Raspberry Pi 3 yang berfungsi untuk menerima data dari modul sensor yang terpasang pada masing-masing node dan akan disimpan pada database MySQL.

Dari beberapa Studi Pustaka di atas, dapat di simpul kan bahwa banyak penelitian yang telah dilakukan mengenai pentingnya sebuah alat untuk memonitoring yang bisa digunakan sebagai acuan untuk mengambil keputusan. Di mana dalam penelitian ini apakah suatu website dikatakan berkualitas atau tidak bahkan populer atau tidaknya di kalangan para pengunjung.

\section{HASIL DAN PEMBAHASAN}

Setelah dilakukan penelitian bahwa website PESSTA+ pada Perguruan Tinggi Raharja menggunakan stat counter di mana setiap kali pengunjung melakukan kunjungan ke dalam website PESSTA+ maka akan menambah angka pada unique visit. Meskipun dalam sehari pengunjung dapat mengunjungi beberapa kali website PESSTA+, angka pada visitor counter akan terus bertambah.

Stat counter juga dapat di setting agar menghitung berdasarkan unique visit, selain itu stat counter menyediakan perhitungan dengan beberapa kategori yang dapat di jadi kan data dan informasi yang memiliki fungsi untuk pengunjung maupun pengelola website. Beberapa kategori yang ada pada stat counter diantaranya returning visits, first time visits, unique visits, 
page view. Unique visit merupakan hasil dari perhitungan returning visits, dan first visit. Dan juga stat counter menyediakan email report yang dapat di setting untuk dikirimkan setiap minggu, bulan maupun setahun sekali.

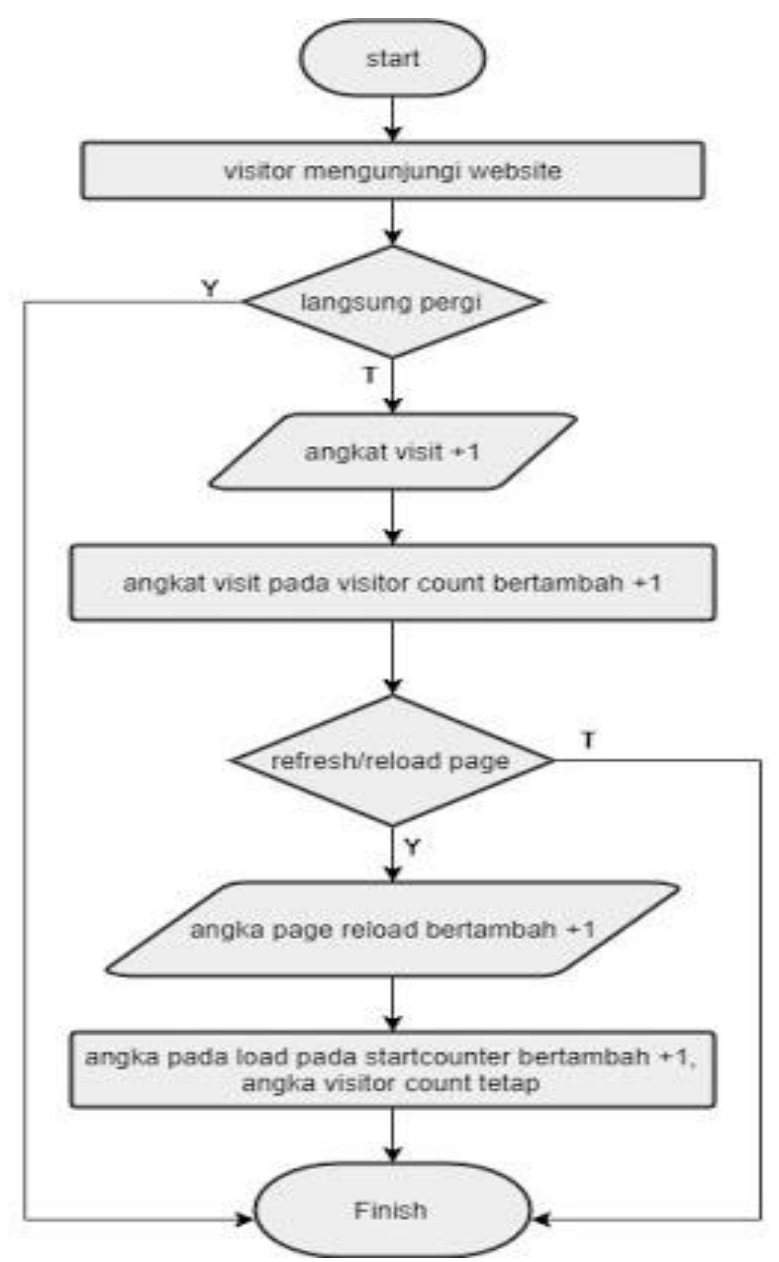

Gambar 3. Flowchart sistem PESSTA+

Seperti yang digambarkan pada gambar 3 di atas, dapat kita lihat bahwa sistem perhitungan menggunakan stat counter berdasarkan seorang pengunjung (visitor) yang mengunjungi website PESSTA+ tersebut. Dan juga perhitungan pada angka pengunjung baru akan dilakukan apabila pengunjung tetap membuka website PESSTA+ selama beberapa saat, tidak langsung meninggal kan website. 


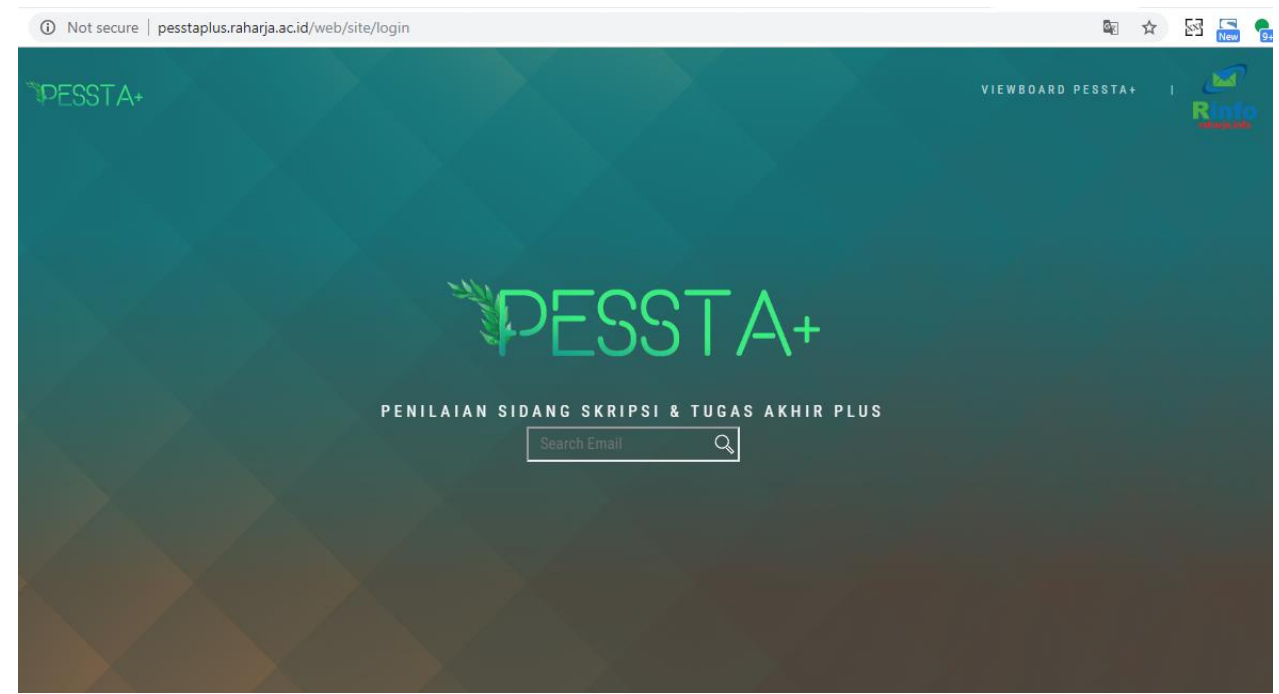

Gambar 4. Tampilan awal website PESSTA+ http://pesstaplus.raharja.ac.id/web/site/login

Gambar 4 merupakan tampilan halaman awal pada website PESSTA+. Pada halaman awal seperti gambar di atas dapat kita lihat terdapat beberapa pilihan menu seperti Konsep Desain, Viewboard dan juga News yang berkaitan dengan Perguruan Tinggi Raharja.

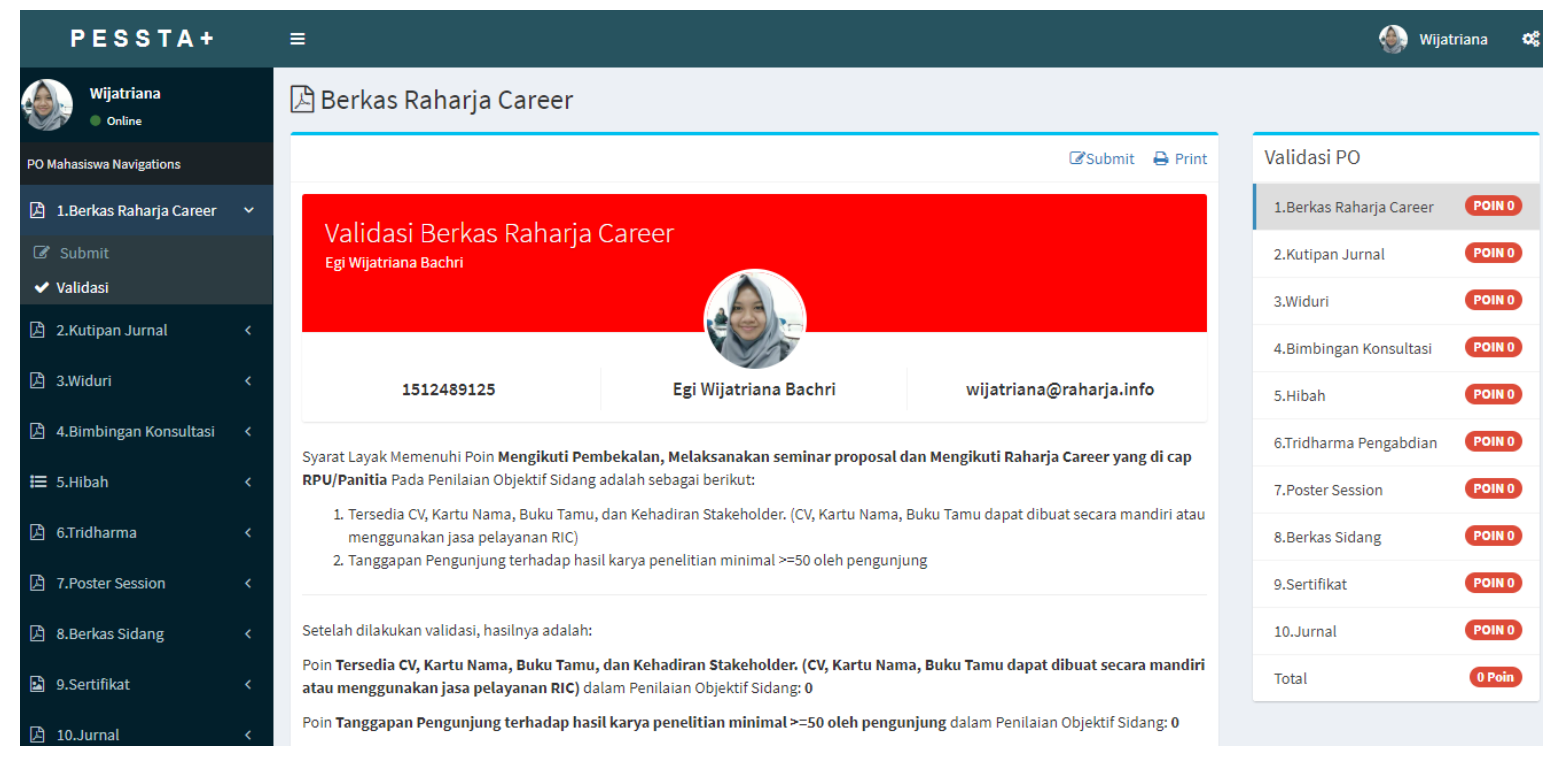

\section{Gambar 5 Halaman Validasi PESSTA+}

Gambar 5 merupakan tampilan home pada website PESSTA+ yang didalamnya terdapat 10 PO (Penilaian Objektif) yang akan digunakan untuk Penilaian Sidang TA/Skripsi. Dimana pada halaman ini digunakan mahasiswa untuk mensubmit Penilaian Objektif yang terdiri dari 10 Penilaian yang dapat membantu untuk nilai akhir mahasiswa. 
Gambar 6. Tampilan unique visit pada website PESSTA+

Gambar 6 merupakan tampilan unique visit yang terdapat didalam website PESSTA+, dapat dilihat bahwa gambar di atas adalah angka yang ditampilkan pada counter untuk mengetahui jumlah pengunjung yang telah mengunjungi website PESSTA + . Dapat kita lihat bersama bahwa saat ini telah ada 35.793 ribu pengunjung (visitor) yang telah mengunjungi website PESSTA+.

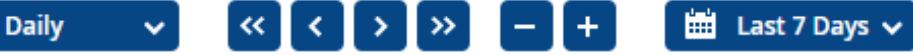

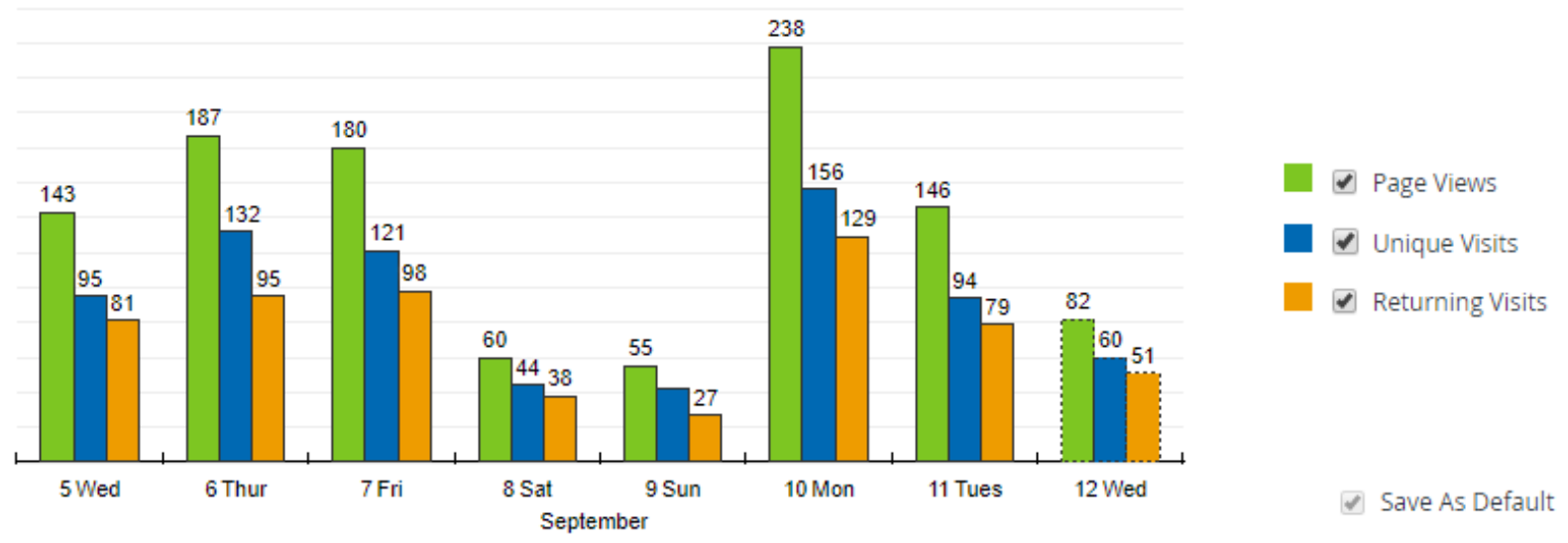

Gambar 6. Tampilan Summary Stats

Gambar 6 merupakan grafik aktivitas pengunjung yang mengunjungi website PESSTA+ yang ditampilkan stat counter. Kita dapat memperoleh secara langsung selama stat counter dipasang pada website PESSTA+ Perguruan Tinggi Raharja yang disajikan dalam bentuk grafik yang dapat memudahkan pengelola dalam memonitoring aktivitas kunjungan yang mengunjungi website PESSTA+ baik harian, bulanan atau pun tahunan.

Grafik yang disajikan juga menampilkan beberapa kategori seperti Page View, Unique Visit, Returning Visits. Page View merupakan banyak nya angka yang mengunjungi halaman PESSTA+, Unique Visit banyak nya pengunjung unik, dan Returning Visits banyaknya angka pengujung yang kembali mengunjungi website PESSTA+ Perguruan Tinggi Raharja. 


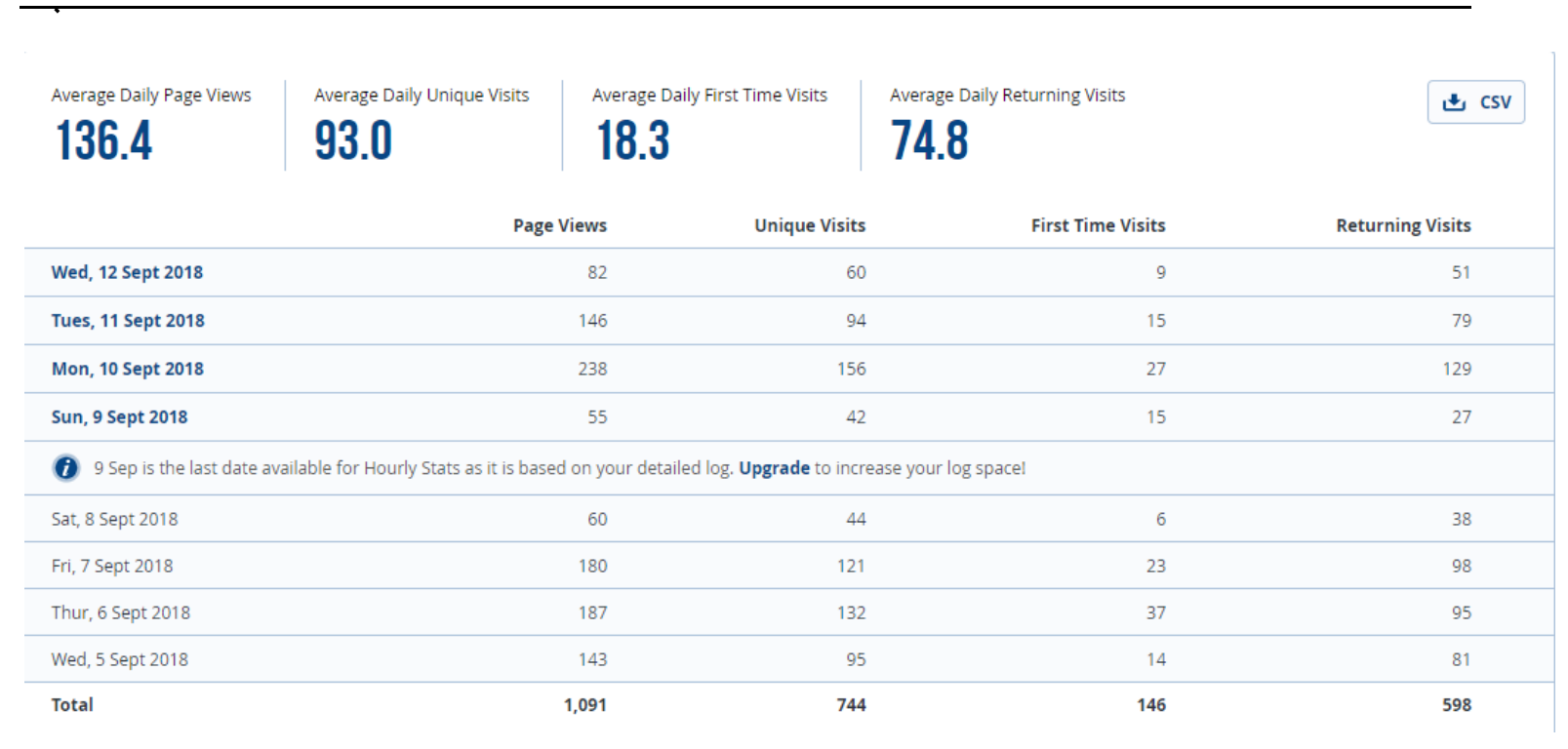

Gambar 7. Tampilan Rekapan Kunjungan website PESSTA+

Gambar 7 merupakan tampilan rekapan kunjungan website PESSTA+ yang ditampilkan stat counter, disajikan secara lengkap dan sangat detail secara keseluruhan per minggu nya. Pada bagian tampilan ini, pengelola dapat memonitoring kuantitas kunjungan pada website. Dari Gambar 7 dapat kita ketahui rekap kunjungan dari tanggal 9 April 2018-16 April 2018 terdapat sebanyak 1.091 Page view, 744 unique visits, 146 first time visits, 598 returning visits.

\section{KESIMPULAN}

Berdasarkan hasil penelitian di atas yang membahas tentang penerapan stat counter sebagai alat monitoring pada website PESSTA+ Perguruan Tinggi Raharja, pengguna stat counter pada penelitian ini dapat terbukti memberikan hasil yang lebih baik dengan keunggulan yang dimiliki oleh stat counter. Data dan informasi yang dapat dihasilkan oleh stat counter sangat informatif bagi pengelola maupun pengunjung. Informatif di sini memiliki arti data dan informasi yang dihasilkan sangat besar nilai gunanya bagi pengelola untuk memonitoring website PESSTA+ pada Perguruan Tinggi Raharja. Dan juga bagi pengunjung (visitor) dapat mengetahui sudah berapa banyak pengunjung yang mengunjungi website PESSTA+.

\section{SARAN}

Penggunaan stat counter untuk memonitoring website PESSTA+ pada Perguruan Tinggi Raharja adalah salah satu langkah yang cukup baik untuk pengembangan pada website PESSTA+. Namun pengembangan nya dapat dilakukan menjadi lebih baik lagi agar menghasilkan sebuah alat monitoring yang berkualitas terhadap aktivitas kunjungan website PESSTA+ Perguruan Tinggi Raharja. Pengelola pun dapat ,menambahkan alat monitoring lainnya yang dapat memenuhi kekurangan yang terdapat pada stat counter.

\section{UCAPAN TERIMA KASIH}

Peneliti mengucapkan terimakasih kepada para pihak yang membantu dalam menyelesaikan penelitian ini. Terutama kepada Tuhan Yang Maha Esa, karena berkat rahmat dan hidayah-Nya sehingga peneliti dapat menyelesaikan penelitian ini. Dan juga mengucapkan 
terimakasih kepada penulis 1 dan penulis 2 yang mana juga sebagai pembimbing selama penelitian ini berlangsung. Terimakasih juga kepada STMIK Raharja yang sudah menyediakan tempat dalam penelitian ini, dan kepada pengelola PESSTA+ yang sudah membantu dan memberi arahan nya.

\section{DAFTAR PUSTAKA}

[1] Handayani, I., Sani, M., \& Sari, D. R. (2016). Penerapan Statcounter sebagai Alat Monitoring Aktivitas Website Hibah Perguruan Tinggi Raharja. Creative Information Technology Journal, 4(1), 18-29.

[2] Amalia, I., \& Karmilasari, K. (2011). Analisis Kepopuleran Website Ukm Dengan Metode Survey Dan Perangkat Bantu Seo Dan Trace Visitor. Proceeding PESAT (Psikologi, Ekonomi, Sastra, Arsitektur \& Sipil), 4.

[3] Jewel, M. H., Islam, M. N., \& Hasan, M. J. (2017). Automatic Room Light Control Using Bidirectional Visitor Counter and Gas Detection (Doctoral dissertation, East West University).

[4] Youssi, O. R., Muttaqin, A., \& Maulana, E. (2018). SISTEM SWITCHING DAN MONITORING TEGANGAN DAN ARUS PADA SMART GRID BERBASIS RASPBERRY PI 3 TERINTEGRASI DENGAN MEDIA SOSIAL DAN WEBSITE. Jurnal Mahasiswa TEUB, 5(6).

[5] Waradkar, G., Ramina, H., Maitry, V., Ansurkar, T., Rawat, M. A., \& Das, M. P. (2016). Automated Room Light Controller with Visitor Counter. Imperial Journal of Interdisciplinary Research, 2(4).

[6] Al-Radaideh, A., Al-Ali, A. R., Bheiry, S., \& Alawnah, S. (2015, March). A wireless sensor network monitoring system for highway bridges. In Electrical and Information Technologies (ICEIT), 2015 International Conference on (pp. 119-124). IEEE.

[7] Tenggono, A., Wijaya, Y., \& Kusuma, E. (2015). Sistem Monitoring dan Peringatan Ketinggian Air berbasis Web dan SMS Gateway. SISFOTENIKA, 5(2).

[8] Jumri, J. P. (2013). Perancangan Sistem Monitoring Konsultasi Bimbingan Akademik Mahasiswa dengan Notifikasi Realtime Berbasis SMS Gateway. Jurnal Sistem dan Teknologi Informasi (JustIN), 1(1), 21-25.

[9] Nataliana, D., Syamsu, I., \& Giantara, G. (2014). Sistem Monitoring Parkir Mobil menggunakan Sensor Infrared berbasis RASPBERRY PI. ELKOMIKA: Jurnal Teknik Energi Elektrik, Teknik Telekomunikasi, \& Teknik Elektronika, 2(1), 68.

[10] Dien, A., Rais, N., \& Rechandini, A. (2018). Pengembangan Sistem Informasi Monitoring Transaksi Gas Elpiji PT. Amrin Jami Indonesia Tigaraksa. Technomedia Journal, 3(1), 73-83. https://doi.org/https://doi.org/10.5281/zenodo.1409449

[11] Novianta, M. A., \& Setyaningsih, E. (2015). Sistem Informasi Monitoring kereta api berbasis web server menggunakan layanan GPRS. Jurnal Momentum, 17(2).

[12] Rahardja, U., Lutfiani, N., \& Rahmawati, R. (2018). Persepsi Mahasiswa Terhadap Berita Pada Website APTISI. SISFOTENIKA, 8(2), 117-127.

[13] Muslihudin, Muhamad, Oktafianto. 2016. Analisis dan Perancangan Sistem Informasi Menggunakan Model Terstruktur dan UML. Yogyakarta: CV. Andi Offset 